\title{
Outcome of laparoscopic repair of perforated duodenal ulcers
}

Hisham Aljohary ${ }^{1}$, fRCS, CABS, Hassan Althani ${ }^{1}$, FRCS, CABS, Gameela Elmabrok ${ }^{1}$, FACHARZT, Khairy $\underline{\text { Hajaji }}^{1}$, MSc, MRCS, Ibrahim Taha ${ }^{1}$, MRCS, CABS

INTRODUCTION Laparoscopic simple closure (LSC) coupled with Helicobacter pylori eradication is a well-recognised treatment for perforated duodenal ulcers. This study aimed to evaluate its safety and efficacy.

METHODS This was a retrospective cohort study conducted on patients who underwent LSC of perforated duodenal ulcers from January 2002 to December 2009. Patients were stratified according to the American Society of Anesthesiologist classification and Boey's risk score.

RESULTS Of the 213 patients, 22 (10.3\%) were excluded as they required conversion to open surgery. 191 (89.7\%) patients who underwent successful laparoscopic repair were included in the study. The median age of the patients was 39 (range 19-73) years, and the majority were male $(n=180,94 \%)$. Median duration of pre-hospital symptoms was eight hours and median time from admission to surgery was six hours. Median operative time was 65 minutes and median hospital stay was five days. Ten patients (median age 53.5 years) required intensive care unit admission. Two patients developed leakage from the suture line - one required re-exploration and the other was managed conservatively. Four patients had intra-abdominal abscesses - one required re-exploration, while three were managed by percutaneous radiological drainage. One patient developed pneumonia and one had pulmonary embolism. There were no surgical site infections. All patients were followed up as surgical outpatients (median duration 36 days). None of the patients required definitive surgery. There was one death in the cohort.

CONCLUSION LSC of perforated duodenal ulcers is a reliable, safe and minimally invasive procedure that has low morbidity.

Keywords: H. pylori eradication, laparoscopic repair, perforated peptic ulcer, proton pump inhibitors, triple therapy

\section{INTRODUCTION}

Despite a significant reduction in the number of elective surgeries performed for peptic ulcers, the incidence of complications such as bleeding, obstruction and perforation has remained steady. Perforation is the second most common complication of duodenal ulcers, and it is the second most frequent type of abdominal perforation that requires surgery, after perforated appendicitis. Since Mouret et al first described the laparoscopic repair of perforated peptic ulcers in 1990, ${ }^{(1)}$ it has been gaining popularity, especially in recent years. This approach allows not only the identification of the site and pathology of perforation but also the closure of the perforation and adequate peritoneal lavage without a large incision.

The first laparoscopic repair of perforated duodenal ulcer was performed at our centre in 1995. A total of 346 surgeries have since been performed from 1995 to 2009. This study reports our experience from January 2002, when an operation room registry was established at our hospital. We evaluated the efficacy and safety of laparoscopic simple closure (LSC) of perforated duodenal ulcers, and assessed the morbidity, rate of conversion to open surgery, follow-up management and incidence of recurrence in patients during the study period.

\section{METHODS}

This was a retrospective cohort study conducted on consecutive patients who underwent laparoscopic repair of perforated duodenal ulcers from January 2002 to December 2009. The operation room registry database was used to search for consecutive patients, following which the medical records of these patients were reviewed. A total of 213 patients were identified from the registry and medical records using the International Classification of Diseases, 9th Revision (ICD-9) codes. Patients were stratified according to the American Society of Anesthesiologist (ASA) classification and Boey's score for risk factors.

All patients showed signs of peritonitis. Perforation was confirmed by erect chest radiographs that showed free air under the diaphragm. Patients' data, clinical history, duration of abdominal pain, operation time, intra- and postoperative complications, reasons for conversion to open surgery, length of hospital stay and postoperative outcomes were entered into the database for analysis. Initial management included intravenous fluid resuscitation and administration of $\mathrm{H} 2$-blocker and prophylactic antibiotics. The patient was kept nil per mouth and a nasogastric tube was inserted.

Surgery was carried out with the patient under general anaesthesia and in supine position, with the operating surgeon standing on the patient's left side. Operating time was measured from the time of skin incision to skin closure. Three ports were used - one 10-mm port and two 5-mm ports. The 10-mm port was inserted above the umbilicus in order to introduce the laparoscope. Under direct vision, the two 5-mm working ports

${ }^{1}$ Department of General Surgery, Hamad General Hospital, Doha, Qatar

Correspondence: Dr Hisham Aljohary, Consultant General Surgeon, Department of General Surgery, Hamad General Hospital, Hamad Medical Corporation, PO 3050, Doha, Qatar. dr.johary@hotmail.com 
were inserted into both the lumbar regions in the midclavicular line. The peritoneal cavity was then inspected. After the site and size of the perforation was determined, the perforation was closed using a single stitch by the intracorporeal knot-tying technique. The same suture was used to anchor a piece of the greater omentum over the perforation. At the end of the procedure, the abdominal cavity was thoroughly irrigated with several litres of saline solution. Drains were inserted according to the surgeon's preference. Nasogastric suction was continued during the first postoperative day. On the second postoperative day, after resumption of oral intake, all patients were started on triple therapy (clarithromycin, metronidazole and omeprazole) for ten days. Patients were followed up in outpatient clinics, and follow-up endoscopy was arranged for patients after six months.

\section{RESULTS}

A total of 213 patients underwent laparoscopic repair of perforated duodenal ulcers. Of these, $22(10.3 \%)$ patients were excluded from the study, as they required conversion to open surgery. The reasons for conversion included excessive peritoneal contamination ( $n=14)$, adhesions $(n=5)$ and inadequate ulcer localisation $(n=3)$. Laparoscopic repair of perforated duodenal ulcers was successful in the remaining 191 (89.7\%) patients. Table I shows the demographics and characteristics of the cohort. The median age of the patients was 39 (range 19-73) years, while that of female patients was 50 years. The majority of patients were male. The median pre-hospital duration of symptoms was 8 (range 3-72) hours and the median time from hospital admission to surgery was 6 (range 1-12) hours. Examination of possible risk factors revealed that 15 (7.9\%) patients had a history of nonsteroidal anti-inflammatory drug intake and 7 (3.7\%) had a history of duodenal ulcers. Overall, 88 (46.1\%) patients were smokers and 19 (9.9\%) were alcohol consumers.

According to ASA classification, 58 (30.4\%) patients were classified as ASA I, 83 (43.5\%) patients were ASA II, 43 (22.5\%) patients were ASA III and 7 (3.7\%) patients were ASA IV (Table I). Based on Boey's score for risk factors, 153 (80.1\%) patients had a score of $0,36(18.8 \%)$ had a score of 1 , and only one patient scored 2. This latter patient died of heart failure. The median surgery time was 65 (range 25-190) minutes. The median size of ulcers was 1 (range $0.5-1.5$ ) cm. All ulcers were amenable to single-stitch laparoscopic repair. The median length of hospital stay was 5 (range $2-30$ ) days (Table I).

In all, 12 (6.3\%) patients developed complications (Table I). Leakage from the suture line was encountered in two patients - one patient had generalised peritonitis and sepsis requiring re-exploration, and the other had a high output from the abdominal drain which responded to one week of conservative treatment (included nasogastric suction and octreotide). Four patients developed intra-abdominal abscesses that were amenable to percutaneous radiological drainage, except for one patient who required re-exploration. Four patients who developed postoperative paralytic ileus had prolonged hospital stay, but
Table I. Patient characteristics $(\mathbf{n}=191)$.

\begin{tabular}{|c|c|}
\hline Variable & No. (\%) \\
\hline \multicolumn{2}{|l|}{ Gender } \\
\hline Male & $180(94.2)$ \\
\hline Female & $11(5.8)$ \\
\hline Age* (yrs) $^{*}$ & $39(19-73)$ \\
\hline Duration of symptoms* (hrs) & $8(3-72)$ \\
\hline Time from admission to surgery* (hrs) & $6(1-12)$ \\
\hline Duration of operation* (min) & $65(25-190)$ \\
\hline Length of hospital stay* (days) & $5(2-30)$ \\
\hline Length of follow-up period* (days) & $36(10-365)$ \\
\hline Size of ulcers $(\mathrm{cm})$ & $1(0.5-1.5)$ \\
\hline \multicolumn{2}{|l|}{ Risk factors } \\
\hline Smoking & $88(46.1)$ \\
\hline Alcohol consumption & $19(9.9)$ \\
\hline NSAID intake & $15(7.9)$ \\
\hline History of duodenal ulcer & $7(3.7)$ \\
\hline \multicolumn{2}{|l|}{ Preoperative anaesthesia risk } \\
\hline ASA I & $58(30.4)$ \\
\hline ASA II & $83(43.5)$ \\
\hline ASA III & $43(22.5)$ \\
\hline ASA IV & $7(3.7)$ \\
\hline \multicolumn{2}{|l|}{ Postoperative complication } \\
\hline Leakage & $2(1.0)$ \\
\hline Intra-abdominal abscess & $4(2.1)$ \\
\hline Prolonged ileus & $4(2.1)$ \\
\hline DVT/pulmonary embolism & $1(0.5)$ \\
\hline Pneumonia & $1(0.5)$ \\
\hline
\end{tabular}

*Data is presented as median (range).

ASA: American Society of Anesthesiologists; DVT: deep venous thrombosis; NSAID: nonsteroidal anti-inflammatory drug

Table II. Characteristics of patients admitted to the intensive care unit $(\mathbf{n}=\mathbf{1 0})$.

\begin{tabular}{llll}
\hline $\begin{array}{l}\text { Age (yrs)/ } \\
\text { gender }\end{array}$ & Nationality & $\begin{array}{l}\text { Reason for ICU } \\
\text { admission }\end{array}$ & ASA status \\
\hline 56/M & Thai & Septic shock & III \\
73/M & Qatari & CAD & III \\
50/M & Pakistani & CAD & IV \\
30/M & Nepalese & Septic shock & II \\
48/M & Indian & CAD & IV \\
30/M & Indian & Septic shock & II \\
58/M & Bangladeshi & Septic shock & III \\
51/M & Bangladeshi & Pulmonary & IV \\
& & embolism & \\
68/F & Qatari & Septic shock + CAD & IV \\
70/F & Qatari & Septic shock & III \\
\hline
\end{tabular}

ASA: American Society of Anesthesiologists; CAD: coronary artery disease F: female; ICU: intensive care unit; M: male

all four responded to nasogastric suction. One patient required treatment for pneumonia, while another was transferred to the intensive care unit (ICU) due to pulmonary embolism. There were no instances of surgical site infections.

Ten patients (ASA II $n=2 ;$ ASA III $n=4$; ASA IV $n=4$; median age 53.5 years) were admitted to the ICU (Table II). The reasons for ICU admission included coronary artery disease (CAD), septic shock and pulmonary embolism. The four patients with a history of CAD were classified as ASA III $(n=1)$ and ASA IV $(n=3)$. 
Table III. Comparison of studies on laparoscopic repair of perforated peptic ulcers in Asian and European cohorts.

\begin{tabular}{|c|c|c|c|c|}
\hline Study & Country & Sample size & Male-to-female ratio & Median age (yrs) \\
\hline Mehendale et al(18) & India & 34 & $33: 1$ & 38 \\
\hline Kok et al $\left.\right|^{(19)}$ & Brunei & 11 & $10: 1$ & 39 \\
\hline Robertson et al(20) & UK/Australia & 20 & $11: 9$ & 62 \\
\hline Naesgaard et al(21) & Norway & 25 & $10: 15$ & 69 \\
\hline Miserez et al ${ }^{(22)}$ & Germany & 18 & $10: 8$ & 50 \\
\hline Mastuda et al(23) & Japan & 14 & $12: 2$ & 39.8 \\
\hline Present study & Qatar & 191 & $180: 11$ & 41 \\
\hline
\end{tabular}

One of these four patients, a 68-year-old woman (ASA IV) died due to severe sepsis and cardiac decompensation. The six patients who presented with septic shock were admitted to the ICU preoperatively. One patient was transferred to the ICU postoperatively due to pulmonary embolism.

All the patients were followed up as surgical outpatients. The median follow-up period was 36 (range 10-365) days. Only $42(22.0 \%)$ patients underwent follow-up endoscopy - 15 (35.7\%) patients had normal endoscopy, another 15 (35.7\%) had healed ulcer, 7 (16.7\%) had gastritis and 5 (11.9\%) had oesophagitis. The Campylobacter-like organism (CLO) test was negative in all scoped patients. None of the patients required definitive surgery.

\section{DISCUSSION}

Perforation of duodenal ulcers affects nearly $10 \%$ of patients and accounts for more than $70 \%$ of deaths associated with the disease. ${ }^{(2)}$ Treatment for this condition is essentially surgical. ${ }^{(2)}$ Although different techniques of ulcer repair have been described, suture repair of the perforation with an omental patch is the most popular technique. ${ }^{(3,4)}$ Other types of laparoscopic repair include single-stitch laparoscopic omental patch repair, ${ }^{(2)}$ simple repair alone, ${ }^{(5)}$ the suture-less technique, ${ }^{(6)}$ stapled omental patch repair, ${ }^{(7)}$ laparoscopic repair with a falciform ligament patch ${ }^{(8)}$ and gastroscopy-aided repair. ${ }^{(9)}$

Studies on laparoscopic repair of perforated peptic ulcers with minimally invasive techniques have shown decreased postoperative analgesia requirements, lower incidence of wound infection, shorter hospital stay and earlier return to work. ${ }^{(6)}$ A systematic review of seven prospective and eight retrospective studies ( $n=1,113$ ) by Lunevicius and Morkevicius indicated statistically significant reductions in the use of analgesics, length of hospital stay, wound infection and mortality rate..$^{(10)}$ A meta-analysis of 13 trials found that laparoscopic repair was associated with significantly lower wound infection rates, reduced postoperative pain and decreased analgesic consumption. ${ }^{(11)}$ However, a Cochrane review of two randomised clinical trials showed no statistically significant differences in the incidence of abdominal septic complications between laparoscopic and open surgery. ${ }^{(12)}$

Although Helicobacter pylori (H. pylori) is a major cause of peptic ulcers, acid reduction procedures are not required for this group of patients, as recurrence of post-eradication ulcer is uncommon. ${ }^{(13)} H$. pylori infection has been shown to be strongly related to economic conditions and age. ${ }^{(14)}$ In developing countries, H. pylori infection occurs in younger patients, frequently during infancy, and reaches a prevalence of $70 \%-90 \%$ in some regions. The incidence of $H$. pylori infection is several times higher in developing countries than in developed countries. ${ }^{(15)}$ A European study demonstrated that the incidence of perforated peptic ulcer has remained nearly constant over the past 50 years, although the median age of patients has increased from 41 years to 62 years and the male-to-female ratio has fallen from 10:1 to 1.5:1. ${ }^{(16)}$ A regional study by Bener et al found a high prevalence of H. pylori infection among workers of low socioeconomic status. ${ }^{(17)}$

Keeping in mind the high prevalence of $H$. pylori infection reported by regional and international studies, ${ }^{(15,17)}$ all our patients were empirically started on triple therapy once they were able to eat postoperatively. The patients in our series were younger (median age 39 years), although female patients were older (median age 50 years), and there was a male preponderance (male-to-female ratio 17:1). The younger age and male predominance in our cohort was due to the fact that threequarters of our patients were workers of low socioeconomic backgrounds from the Indian subcontinent who have a high rate of $H$. pylori infection. This is in keeping with Mehendale et al's study from India, which reported a median age of 38 years and a male-to-female ratio of 33:1. ${ }^{(18)}$ Studies from Europe, however, reported older patients and a much lower male predominance. Table III shows a comparison of the studies conducted on laparoscopic repair of perforated peptic ulcers in cohorts from Europe and Asia. ${ }^{(18-23)}$

The conversion rates of laparoscopic surgery to open repair have been reported to range from $0 \%$ to $27 \%$, (5,6,18,23-28) which are comparable to the rate of $10.3 \%(22 / 213)$ in our study. The reasons for conversion in our series included excessive peritoneal contamination ( $n=14)$, adhesions $(n=5)$ and inadequate ulcer localisation $(n=3)$. Although drains were used routinely at the beginning of our study, they were seldom used subsequently. The decision to convert to open surgery and the use of drains were largely based on the individual surgeon's preference.

Despite its increasing popularity, the use of laparoscopic repair to treat perforated peptic ulcers remains controversial due to concerns regarding a longer operation time, leakage and the high rate of reoperation. ${ }^{(11,19)}$ Table IV shows a comparison of the median operation time, length of hospital stay and patient outcomes among various studies. . $5,6,18,23,27,28)$ Postoperative 
Table IV. Comparison of outcomes of various studies on laparoscopic repair of perforated peptic ulcers.

\begin{tabular}{|c|c|c|c|c|c|c|c|c|}
\hline Study & $\begin{array}{l}\text { Sample } \\
\text { size }\end{array}$ & $\begin{array}{l}\text { Median } \\
\text { age (yrs) }\end{array}$ & $\begin{array}{c}\text { Male-to- } \\
\text { female } \\
\text { ratio }\end{array}$ & $\begin{array}{c}\text { Conversion } \\
\text { (\%) }\end{array}$ & $\begin{array}{c}\text { Median } \\
\text { operation } \\
\text { time (min) }\end{array}$ & $\begin{array}{l}\text { Median length } \\
\text { of hospital } \\
\text { stay (days) }\end{array}$ & $\begin{array}{c}\text { Morbidity } \\
\text { (\%) }\end{array}$ & $\begin{array}{c}\text { Mortality } \\
\text { (\%) }\end{array}$ \\
\hline Seelig et al(5) & 24 & 49 & $16: 8$ & 12 & 65 & 9 & 12 & 0 \\
\hline Lau et al ${ }^{(6)}$ & 24 & 52 & $20: 4$ & 20 & 112 & 5 & 21 & 0 \\
\hline Mehendale et $\mathrm{al}^{(18)}$ & 34 & 38 & $33: 1$ & 18 & 50 & 4 & NA & 0 \\
\hline Mastuda et al(23) & 14 & 39 & $12: 2$ & 21 & 135 & 17 & 7 & 0 \\
\hline Druart et al $\left.\right|^{(27)}$ & 100 & 52 & $64: 36$ & 8 & 80 & 9 & 9 & 5 \\
\hline Bhogal et al ${ }^{(28)}$ & 19 & 54 & $13: 6$ & 0 & 61 & 3 & 5 & 0 \\
\hline Present study & 191 & 41 & $180: 11$ & 10 & 65 & 5 & 6 & 0.5 \\
\hline
\end{tabular}

NA: not available

complications occurred in $12(6 \%)$ patients in the present study. No surgical site infections were encountered and none of our patients was readmitted for definitive surgery - most probably due to the eradication of $H$. pylori infection using triple therapy, which was also prescribed for patients who required open surgery.

In conclusion, laparoscopic repair of perforated duodenal ulcers is a safe and reliable option that is associated with low morbidity. Coupled with triple therapy, it results in a low incidence of subsequent definitive surgery.

\section{REFERENCES}

1. Mouret P, François $Y$, Vignal J, Barth X, Lombard-Platet R. Laparoscopic treatment of perforated peptic ulcer. Br J Surg 1990; 77:1006

2. Siu WT, Leong HT, Li MK. Single stitch laparoscopic omental patch repair of perforated peptic ulcer. J R Coll Surg Edinb 1997; 42:92-4.

3. Nathanson LK, Easter DW, Cuschieri A. Laparoscopic repair/peritoneal toilet of perforated duodenal ulcer. Surg Endosc 1990; 4:232-3.

4. Sunderland GT, Chisholm EM, Lau WY, et al. Laparoscopic repair of perforated peptic ulcer. Br J Surg 1992; 79:785.

5. Seelig MH, Seelig SK, Behr C, Schönleben K. Comparison between open and laparoscopic technique in the management of perforated gastroduodenal ulcers. J Clin Gastroenterol 2003; 37:226-9.

6. Lau WY, Leung $\mathrm{KL}$, Kwong $\mathrm{KH}$, et al. A randomized study comparing laparoscopic versus open repair of perforated peptic ulcer using suture or sutureless technique. Ann Surg 1996; 224:131-8.

7. Darzi A, Cheshire NJ, Somers SS, et al. Laparoscopic omental patch repair of perforated duodenal ulcer with an automated stapler. Br J Surg 1993; 80:1552.

8. Munro WS, Bajwa F, Menzies D. Laparoscopic repair of perforated duodenal ulcers with a falciform ligament patch. Ann R Coll Surg Engl 1996; 78:390-1.

9. Costalat G, Alquier Y. Combined laparoscopic and endoscopic treatment of perforated gastroduodenal ulcer using the ligamentum teres hepatic (LTH). Surg Endosc 1995; 9:677-9.

10. Lunevicius R, Morkevicius M. Systematic review comparing laparoscopic and open repair for perforated peptic ulcer. Br J Surg 2005; 92:1195-207.

11. Lau H. Laparoscopic repair of perforated peptic ulcer: a meta-analysis. Surg Endosc 2004; 18:1013-21.

12. Sanabria AE, Morales CH, Villegas MI. Laparoscopic repair for perforated peptic ulcer disease. Cochrane Database of Syst Rev 2005; 4:CD004778.

13. Siu WT, Leong HT, Law BK, et al. Laparoscopic repair for perforated peptic ulcer: a randomized controlled trial. Ann Surg 2002; 235:313-9.

14. Celiński K, Kurzeja-Mirosław A, Słomka M, et al. The effects of environmental factors on the prevalence of Helicobacter pylori infection in inhabitants of Lublin Province. Ann Agric Environ Med 2006; 13:185-91.

15. Bardhan PK. Epidemiological features of Helicobacter pylori infection in developing countries. Clin Infect Dis 1997; 25:973-8.

16. Svanes C, Salvesen H, Stangeland L, Svanes K, Søreide O. Perforated peptic ulcer over 56 years. Time trends in patients and disease characteristics. Gut 1993; 34:1666-71.

17. Bener A, Uduman SA, Ameen A, et al. Prevalence of Helicobacter pylori infection among low socio-economic workers. J Commun Dis 2002; 34:179-84.

18. Mehendale VG, Shenoy SN, Joshi AM, Chaudhari NC. Laparoscopic versus open surgical closure of perforated duodenal ulcers: a comparative study. Indian J Gastroenterol 2002; 21:222-4.

19. Kok KY, Mathew VV, Yapp SK. Laparoscopic omental patch repair for perforated duodenal ulcer. Am Surg 1999; 65:27-30.

20. Robertson GS, Wemyss-Holden SA, Maddern GJ. Laparoscopic repair of perforated peptic ulcers. The role of laparoscopy in generalized peritonitis. Ann R Coll Surg Engl 2000; 82:6-10.

21. Naesgaard JM, Edwin B, Reiertsen $O$, et al. Laparoscopic and open operation in patients with perforated peptic ulcer. Eur J Surg 1999; 165:209-14

22. Miserez M, Eypasch E, Spangenberger W, Lefering R, Troidl H. Laparoscopic and conventional closure of perforated peptic ulcer. A comparison. Surg Endosc 1996; 10:831-36.

23. Matsuda M, Nishiyama M, Hanai T, Saeki S, Watanabe T. Laparoscopic omental patch repair of perforated peptic ulcer. Ann Surg 1995; 221:236-40.

24. Sø JBY, Kum CK, Fernandes ML, Goh P. Comparison between laparoscopic and conventional omental patch repair for perforated duodenal ulcer. Surg Endosc 1996; 10:1060-3.

25. Lee FY, Leung KL, Lai PB, Lau JW. Selection of patients for laparoscopic repair of perforated peptic ulcer. Br J Surg 2001; 88:133-6.

26. Khoursheed M, Fuad M, Safar H, Dashti H, Behbehani A. Laparoscopic closure of perforated duodenal ulcer. Surg Endosc 2000; 14:56-8.

27. Druart ML, Van Hee R, Etienne J, et al. Laparoscopic repair of perforated duodenal ulcer. A prospective multicenter clinical trial. Surg Endosc 1997; 11:1017-20.

28. Bhogal RH, Athwal R, Durkin D, Deakin M, Cheruvu CN. Comparison between open and laparoscopic repair of perforated peptic ulcer disease. World J Surg 2008; 32:2371-4. 